Thorax (1976), 31, 315.

\title{
Quantitation of thick-walled peripheral lung vessels in chronic airways obstruction
}

\author{
K . W . M . S C O T T ${ }^{1}$ \\ Academic Division of Pathology, University of Sheffield
}

\begin{abstract}
Scott, K. W. M. (1976). Thorax, 31, 315-319. Quantitation of thick-walled peripheral lung vessels in chronic airways obstruction. The number of thick-walled peripheral lung vessels (defined as vessels of less than $100 \mu$ diameter with two distinct elastic laminae) was calculated in 50 postmortem lungs. The size of the right ventricle, the amount and type of emphysema, and the proportion of small airways lumen in the lung were also quantitated. Eighteen patients had died as a result of chronic airways obstruction, 17 had symptoms of chronic chest disease but died from some unrelated cause, and 15 had no symptoms related to the respiratory system. The mean number of thick-walled peripheral lung vessels (TWPV) was found to be significantly greater in the fatal disease group than in both the other groups. No significant difference was found between the mean values of the symptomatic and asymptomatic groups. The mean number of TWPV was significantly greater in cases with a right ventricular weight of more than $80 \mathrm{~g}$ than in those with a weight of less than $65 \mathrm{~g}$. Positive correlations were found between the number of TWPV and right ventricular weight, total amount of emphysema in the lung, and the amounts of centrilobular and panlobular emphysema.

Significant negative correlations were found between the number of TWPV and both the ratio of the weight of the left ventricle to the right ventricle and the proportion of small airways lumen in the lung.
\end{abstract}

Several studies have shown that, in cases of emphysema, there is a relationship between the development of thick-walled muscular pulmonary arterioles and right ventricular hypertrophy (Heath and Edwards, 1958; Wagenvoort, Heath, and Edwards, 1964; Hicken et al., 1965). These studies did not quantitate the changes in the pulmonary arterioles. Methods of measuring the thickness of pulmonary arterioles in man and animals under hypoxic conditions have been used by O'Neal, Thomas, and Hartroft (1955), Wagenvoort (1960), Naeye (1962 and 1965), and Hasleton, Heath, and Brewer (1968). These methods are all liable to give distorted results due to shrinkage and contraction of small vessels which may alter the vessel wall thickness. More recently a method of quantitating the number of thick-walled peripheral lung vessels has been devised by Hunter et al. (1974). This was used in a study of pulmonary vessels in hypoxic rats and mice and, as far as is known, has not been applied to human material.

1Present address: Department of Pathology, The Royal Hospital, Wolverhampton
The purpose of the present study is to apply this technique to a series of cases of fatal and non-fatal chronic airways obstruction, to compare the findings with those in a group of patients who died of conditions other than chest disease, and to relate the extent of the changes in the small vessels to other pathological parameters of lung and cardiac disease.

\section{MATERIAL AND METHODS}

The investigation was carried out on hearts and left lungs, obtained at necropsy, from 50 patients. The hearts were fixed, following examination of the coronary arteries, in $10 \%$ formol saline for 72-96 hours and were then dissected according to the method of Fulton, Hutchinson, and Morgan Jones (1952). The right ventricle and the left ventricle plus the septum were weighed separately, and cases which showed evidence of left ventricular hypertrophy (left ventricle plus septum weighing more than $225 \mathrm{~g}$ ) were excluded. Also excluded were cases of systemic hypertension, gross coronary artery disease, and myocardial fibrosis. 
The lungs were inflated with $10 \%$ formol saline introduced by a catheter into the left main bronchus at a pressure of $30 \mathrm{~cm}$ of water, using a modification of the apparatus designed by Heard (1969).

After inflation in this state the lung was then sliced in the parasagittal plane at $1 \mathrm{~cm}$ intervals and, after barium sulphate impregnation (Heard, 1958), three or four slices were examined to determine the amount and type of emphysema present. This was done using a plastic grid and a pointcounting technique (Dunnill, 1962). The type of tissue under each point in the grid was noted, and a count was made of the following components in each slice: panlobular emphysema, centrilobular emphysema, normal lung, and non-parenchymal tissues (blood vessels, bronchi, pleura, etc). The amount of each type of emphysema was expressed as a percentage of the total number of points counted, and a mean was taken of the three or four slices examined. The total amount of emphysema present was also calculated as a percentage. Using a stratified random sampling technique (Dunnill, 1968), six blocks of approximately $2.5 \times 1.5 \times 0.5 \mathrm{~cm}$ were selected from the lung slices. These were embedded in paraffin, sectioned $(5 \mu)$, and stained by haematoxylin and eosin. The relative proportion of small airways of diameter less than $2 \mathrm{~mm}$ was calculated using an eyepiece graticule with 25 equidistant points. Each point was scored as either small airways lumen or other lung tissue, and the proportion of small airways lumen (Q) in the lung was expressed as a percentage of the total number of points counted (Matsuba and Thurlbeck, 1971). It was assumed that shrinkage due to fixation and processing was equal in small airways and in the remainder of the lung tissue, and $Q$ was not corrected for the degree of inflation as Matsuba and Thurlbeck (1972) found this not to be of major significance.

Sections from the same six random blocks were also stained by the Weigert-van Gieson method. Using a $\times 25$ objective lens the whole section was examined to determine the number of small vessels of less than $100 \mu$ in diameter which had a double elastic lamina with a layer of muscle between the laminae. This was done using a modification of the technique of Hunter et al. (1974). All small vessels with a definite elastic coat were counted, and the number of them having a double layer of elastic was expressed as a percentage of the total number of vessels counted. Small venules were included with arterioles as it is very difficult to distinguish them without seeing them join an artery or vein (Brenner, 1935). Vessels of diameter less than $100 \mu$ were counted as this is the upper limit of the size of pulmonary arterioles found by Brenner (1935). The criteria of Hunte et al. (1974) were used to distinguish thick-walle peripheral lung vessels from normal small vessels A double elastic lamina was said to be presente when two laminae, with a space between them $\vec{\rho}$ were visible for at least half the diameter in cross section or at least half the length of the wall iff longitudinal section. When more than two layerst of elastic were present, these vessels were included in the thick-walled peripheral lung vessel group. Clinical details of the patients were obtained fron the case records and this permitted the division of the 50 cases into three separate groups. The first group consisted of 15 cases in whom there was no history of cough, sputum production or breathlessness and death was not due to respira tory disease. The second group consisted of 18 patients who died as a result of chronic airways obstruction. The majority had heart failure, foP which no cause other than lung disease could be found, and many of them had a terminal acute bronchitis. The third group consisted of $1 \bar{t}$ patients who had a clinical history of cough and sputum production consistent with a clinical diag nosis of chronic bronchitis. They had never com plained of breathlessness and all the patients if this group died from conditions other than chronic airways obstruction.

\section{RESULTS ${ }^{1}$}

Table I shows results for the 15 asymptomatie patients, including the right ventricular weight the ratio of the weight of the left ventricle to the right ventricle, the total amount of emphysem in the lung, the amounts of centrilobular and panlobular emphysema, the proportion of smat airways lumen in the lung, and the proportion of thick-walled peripheral lung vessels. Table İ. shows results for the 18 patients with fatal chronif airways obstruction, and Table III shows those for the 17 symptomatic patients with non-fatal res piratory disease. Comparisons of heart weights, amounts of emphysema, and airway changes have been made in a previous study (Scott, 1976). The mean percentage of thick-walled peripheral lun 9 vessels in the fatal disease group was $18.75 \%$. This was significantly greater than the mean in the asymptomatic group of $6.02 \%(t=7.14, \mathrm{P}<0.001 \%$ and the mean in the symptomatic group of $7 \cdot 28 \%$ $(t=6.05, \mathrm{P}<0.001)$. There was no significant differe ence between the mean numbers of thick-walle $\Phi$

${ }^{1}$ Full tabulated data are available on application to the author 
T A B L E I

FIFTEEN ASYMPTOMATIC CASES

\begin{tabular}{l|c|c|c|c|c|c|c}
\hline & RVW (g) & LV/RV & $\begin{array}{c}\text { Total (\%) } \\
\text { Emphysema }\end{array}$ & CLE (\%) & PLE (\%) & Q (\%) & TWPV (\%) \\
\cline { 2 - 6 } Mean & 42.5 & 3.7 & 3.1 & $2 \cdot 7$ & 0.3 & 1.34 & 6.02 \\
\hline
\end{tabular}

RVW = right ventricular weight $; \quad L V / R V=$ ratio of weight of left ventricle plus septum to right ventricle; $C L E=$ centrilobular emphysema $;$ PLE = panlobular emphysema; $Q=$ proportion of small airways $(<2 \mathrm{~mm})$ lumen in the lung; $T W P V=$ proportion of small vessels $(<100 \mu$ diam) with double elastic laminae.

T A B L E I I

EIGHTEEN CASES OF FATAL CHRONIC AIRWAYS OBSTRUCTION

\begin{tabular}{|c|c|c|c|c|c|c|c|}
\hline & RVW (g) & LV/RV & $\begin{array}{c}\text { Total (\%) } \\
\text { Emphysema }\end{array}$ & CLE $(\%)$ & PLE (\%) & Q (\%) & TWPV (\%) \\
\hline $\begin{array}{l}\text { Mean } \\
\text { SD }\end{array}$ & $\begin{array}{r}106 \cdot 2 \\
42.5\end{array}$ & $\begin{array}{l}1 \cdot 86 \\
0 \cdot 7\end{array}$ & $\begin{array}{l}49 \cdot 3 \\
21 \cdot 2\end{array}$ & $\begin{array}{l}11 \cdot 8 \\
12.5\end{array}$ & $\begin{array}{l}38 \cdot 0 \\
29 \cdot 3\end{array}$ & $\begin{array}{l}0.85 \\
0.43\end{array}$ & $\begin{array}{r}18.75 \\
6.50\end{array}$ \\
\hline
\end{tabular}

Abbreviations-see Table I.

T A B L E I I I

SEVENTEEN SYMPTOMATIC CASES OF NON-FATAL RESPIRATORY DISEASE

\begin{tabular}{|c|c|c|c|c|c|c|c|}
\hline & RVW (g) & LV/RV & $\begin{array}{c}\text { Total (\%) } \\
\text { Emphysema }\end{array}$ & CLE $(\%)$ & PLE (\%) & Q (\%) & TWPV (\%) \\
\hline $\begin{array}{l}\text { Mean } \\
\text { SD }\end{array}$ & $\begin{array}{r}46 \cdot 6 \\
9 \cdot 5\end{array}$ & $\begin{array}{l}3 \cdot 35 \\
0 \cdot 6\end{array}$ & $\begin{array}{l}22 \cdot 5 \\
15 \cdot 7\end{array}$ & $\begin{array}{r}10 \cdot 1 \\
8 \cdot 1\end{array}$ & $\begin{array}{l}12 \cdot 4 \\
17 \cdot 2\end{array}$ & $\begin{array}{l}1.36 \\
0.53\end{array}$ & $\begin{array}{l}7 \cdot 28 \\
4 \cdot 44\end{array}$ \\
\hline
\end{tabular}

Abbreviations-see Table I.

peripheral vessels in the symptomatic and asymptomatic groups $(t=0.97, \mathrm{P}>0.30)$.

The mean percentage of thick-walled vessels in the asymptomatic group +2 SD was $10.96 \%$. Only one case (38) in this group fell outside this value at $11.4 \%$. In the group of patients who died from lung disease, two had values of less than $10.96 \%$, case $15(6.5 \%)$ and case $68(10.6 \%)$. Four cases in the symptomatic group had values greater than $10.96 \%$, case $6(17.6 \%)$, case 23 $(15 \cdot 7 \%)$, case $32(17 \cdot 5 \%)$, and case $69(12 \cdot 7 \%)$.

When the 50 cases were divided into two groups, according to the presence of right ventricular hypertrophy, it was found that the mean percentage of thick-walled peripheral lung vessels in 13 cases with a weight greater than $80 \mathrm{~g}$ was $10.39 \%$. This was significantly greater than the mean of the 37 cases with a right ventricular weight of less than $65 \mathrm{~g}: 8.43 \%(t=4.97, \mathrm{P}<0.001)$.

The average number of vessels counted in each case was 494 , the smallest number being 113 in case 73 and the largest number 990 in case 43 .

Correlation coefficients for all 50 cases, when each parameter of lung and cardiac disease was compared to the number of thick-walled peri- pheral lung vessels, are shown in Table IV. There was a significant positive correlation between the number of thick-walled vessels and the right ventricular weight (Figure). Significant positive correlations were also found with the total amount of emphysema and the amounts of centrilobular and panlobular emphysema. Significant negative correlations were present between the number of thick-walled vessels and both the ratio of the weight of the left ventricle to the right ventricle and the proportion of small airways lumen to other tissues in the lung.

\section{T A B L E I V}

CORRELATION COEFFICIENTS BETWEEN EACH PARAMETER MEASURED AND THE PROPORTION OF THICK-WALLED PERIPHERAL LUNG VESSELS

\begin{tabular}{l|c|c}
\hline \multicolumn{1}{c|}{ Parameter } & $\begin{array}{c}\text { Correlation } \\
\text { Coefficient }\end{array}$ & P \\
\hline RVW (g) & +0.597 & $<0.001$ \\
LV/RV & -0.626 & $<0.001$ \\
Total emphysema (\%) & +0.716 & $<0.001$ \\
CLE (\%) & +0.298 & $<0.05$ \\
PLE (\%) & +0.589 & $<0.001$ \\
Q (\%) & -0.289 & $<0.05$ \\
\hline
\end{tabular}

Abbreviations-see Table I. 


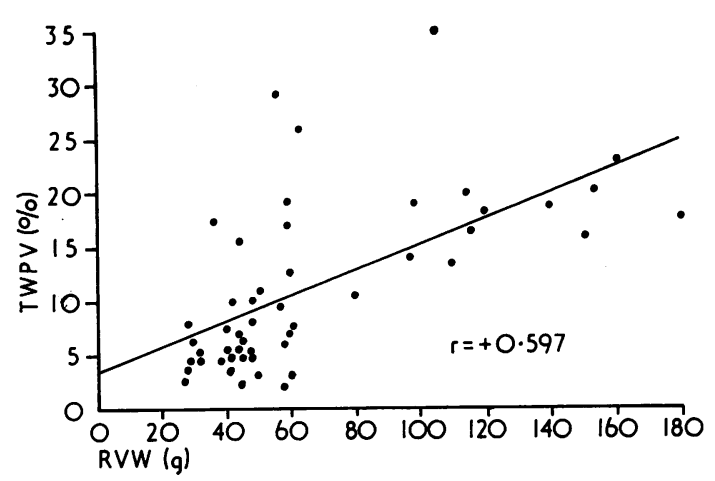

FIGURE The relationship between the right ventricular weight and the percentage of peripheral lung vessels with thick walls.

\section{DISCUSSION}

The presence of muscularized pulmonary arterioles in the lung is widely used as a diagnostic indication of the presence of pulmonary hypertension (Heath and Edwards, 1958; Wagenvoort et al., 1964; Hicken et al., 1965). Although the vast majority of pulmonary arterioles do not normally have a muscular coat, vessels as small as $80 \mu$ in diameter may be found with a muscle layer between two elastic laminae (Heath and Edwards, 1958). The technique used in the present study permits the distinction of normal numbers of muscularized arterioles from the increased numbers found in pulmonary hypertension. The method is fairly rapid, easily performed, and gives a clear distinction between normal and abnormal cases. Only one case, in the group with no chest disease, had a value outside the mean for the group +2 SD, and only two cases in the fatal chest disease group had values within this normal range.

The values obtained in this study were comparable to those found by. Hunter et al. (1974) in experimental hypoxic animals. The mean number of thick-walled peripheral lung vessels in the asymptomatic patients was $6.02 \%$ as compared to $9.6 \%$ in the control group of animals in the study by Hunter et al. The fatal disease group had a mean of $18.75 \%$ as compared to $24.1 \%$ in the hypoxic animals.

A good correlation was obtained between the number of thick-walled peripheral lung vessels in the lung and the size of the right ventricle. This confirms the findings of Hicken et al. (1965), who found a close correlation between the development of muscularized pulmonary arterioles and right ventricular hypertrophy in emphysema. Thiso group also found a predominance of blood vesselo changes in centrilobular as compared to othere types of emphysema. However, this study hasp shown positive correlations between the number of thick-walled vessels and both centrilobular and panlobular emphysema. The reduction in the small airways lumen in the lung has previously $\overrightarrow{.}$ been shown to be important in the development of right ventricular hypertrophy in emphysema (Big non et al., 1968; Bignon, Andre-Bougaran, and Brouet, 1970; Scott, 1976). The present study has shown that there is also a good correlation be tween the loss of small airways lumen and thछ development of thick-walled peripheral lung vessels.

This study has also shown that the number of thick-walled vessels in the lung is related to the clinical severity of chronic airways obstruction. Although no difference was found between the patients without chest disease and those with non? fatal chest disease, there was a significantly greater number of thick-walled peripheral vessels in patients dying from chronic airways obstruction as compared to both the other groups. The majority of patients who die from airways obstruc $\mathbb{2}$ tion have pulmonary hypertension, as shown b the right ventricular weights, and Wagenvoort $e t$ al. (1964) found that only when pulmonary hyper? tension is severe and sustained in emphysema de्ष. the pulmonary arterioles show a distinct mediat between the internal and external elastic laminaeo

I am grateful to Dr. G. R. Barer for helpful advice and to Mrs. Janet Finch for typing the manuscript.

\section{REFERENCES}

Bignon, J., Andre-Bougaran, J., and Brouet, G. (1970) Parenchymal, bronchiolar, and bronchial measurev ments in centrilobular emphysema. Thorax, 25? 556.

Khoury, F., Even, P., Andre, J., and Brouet, G. (1968). Étude anatomique quantitative deg broncho-pneumopathies chroniques obstructivess Résultats préliminaires. Individualisation dอ formes avec bronchiolosténoses disséminées Revue de Tuberculose et de Pneumologie, 32 207.

Brenner, O. (1935). Pathology of the vessels of the pulmonary circulation. Part I. Archives of Inter nal Medicine, 56, 211.

Dunnill, M. S. (1962). Quantitative methods in the study of pulmonary pathology. Thorax, 17, 320. (1968). Quantitative methods in histology. Sanp pling for histological analysis. In Recent A\& 
vances in Clinical Pathology, Series V, p. 405, edited by S. C. Dyke. Churchill, London.

Fulton, R. M., Hutchinson, E. C., and Morgan Jones, A. (1952). Ventricular weight in cardiac hypertrophy. British Heart Journal, 14, 413.

Hasleton, P. S., Heath, D., and Brewer, D. B. (1968). Hypertensive pulmonary vascular disease in states of chronic hypoxia. Journal of Pathology and Bacteriology, 95, 431.

Heard, B. E. (1958). A pathological study of emphysema of the lungs with chronic bronchitis. Thorax, 13, 136.

(1969). Pathology of Chronic Bronchitis and Emphysema, p. 8. Churchill, London.

Heath, D. and Edwards, J. E. (1958). The pathology of hypertensive vascular disease. Circulation, 18, 533.

Hicken, P., Heath, D., Brewer, D. B., and Whitaker, W. (1965). The small pulmonary arteries in emphysema. Journal of Pathology and Bacteriology, 90, 107.

Hunter, C., Barer, G. R., Shaw, J. W., and Clegg, E. J. (1974). Growth of the heart and lungs in hypoxic rodents: A model of human hypoxic disease. Clinical Science and Molecular Medicine, 46, 375 .

Matsuba, K. and Thurlbeck, W. M. (1971). The number and dimensions of small airways in non-emphysematous lungs. American Review of Respiratory Disease, 104, 516.
(1972). The number and dimensions of small airways in emphysematous lungs. American Journal of Pathology, 67, 265.

Naeye, R. L. (1962). Hypoxemia, effects on the pulmonary vascular bed. Medicinae Thoracalis, 19, 494.

(1965). Effect of alpha-methyl-dopa on heart and pulmonary arteries of hypoxic mice. American Journal of Physiology, 209, 702.

O'Neal, R. M., Thomas, W. A., and Hartroft, P. M. (1955). The media of small muscular pulmonary arteries in mitral stenosis. Archives of Pathology, 60, 267.

Scott, K. W. M. (1976). A pathological study of the lungs and heart in fatal and non-fatal chronic airways obstruction. Thorax, 31, 70.

Wagenvoort, C. A. (1960). Vasoconstriction and medial hypertrophy in pulmonary hypertension. Circulation, 22, 535.

Heath, D., and Edwards, J. E. (1964). The Pathology of the Pulmonary Vasculature, p. 331 C. C. Thomas Springfield, Illinois.

Requests for reprints to: Dr. K. W. M. Scott, Department of Pathology, The Royal Hospital, Wolverhampton WV2 1BT. 